\title{
发电厂热能动力系统优化及节能改造分析
}

\section{Analysis of Thermal Power System Optimization and Energy Saving Transformation in Power Plant}

\section{罗嘉文}

\author{
Jiawen Luo
}

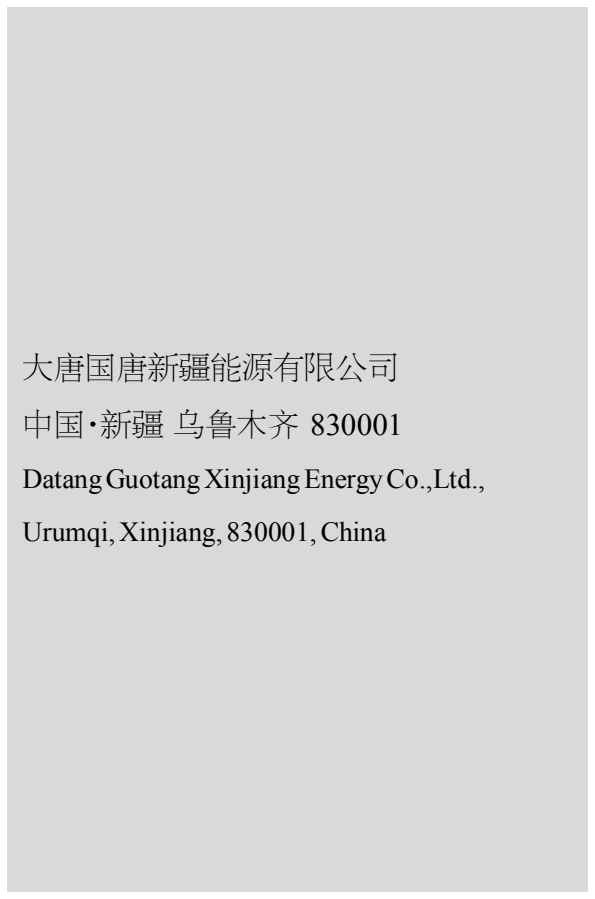

【摘 要】在现代化社会经济的快速发展中,社会各界对发电厂的生产水平、基础设施建 设提出了更加严格的要求。在发电厂运行过程中, 相关工作人员需要深入分析热能动力系 统问题, 并采取相应的措施进行优化,建立完善的生产系统结构,做好热能动力系统优化 和节能改造工作, 这样使得能源的消耗量不断降低, 为发电厂创造更多的收益, 论文主要 对发电厂热能动力系统优化及节能改造进行了分析。

【Abstract】With the rapid development of modern society and economy, all walks of life have put forward more stringent requirements on the production level and infrastructure construction of power plants. In the process of power plant operation, the relevant staff need to in-depth analysis of thermal power system, and adopt corresponding measures to optimize and establish a perfect production system structure, to do a good job of thermal power system optimization and energy saving transformation, so that the energy consumption decrease, create more benefits for power plant, the paper mainly to the power plant heat energy power system optimization and energy saving transformation are analyzed.

【关键词】发电厂; 热能动力系统;优化;节能改造

【Keywords 】power plants; thermal power system; optimization; energy saving transformation 【DOI】10.36012/peti.v2i1.1289

\section{1 引言}

目前, 社会各界越来越关注发电厂的生产水平以及各项 基础设施的工作性能,并对其提出了更高的要求,相关部门需 要针对发电厂生产系统的组成结构进行优化, 提高发电厂的 生产效益,为发电厂的持续、稳定发展提供支持。另外,发电厂 还需要深入分析热能动力系统的实际发展情况, 掌握系统运 行效率的各项影响因素。基于此,文章阐述了热能动力系统的 相关内容, 介绍了发电厂热能动力系统优化及节能改造要点, 并对发电厂中热能与动力工程的优化对策进行了分析。

\section{2 热能动力系统概述}

在发电厂运行过程中, 热能动力系统指的是在整个发电 设备和发电过程中, 具备节能潜力的系统, 其能够有效地解决 资源问题和环境污染问题, 发电厂需要加强对热能发电动力 系统的优化, 坚持可持续发展理念,引进现代化技能技术,为 发电厂创造更多的经济效益 ${ }^{[1]}$ 。因此, 为了实现节能减排的预 期目标, 做好绿色发电工作, 相关部门需要优化热能发电动力
系统, 热能发电动力系统主要是将热能转化成机械能, 利用热 胀冷缩, 在高温环境中获取更多能源, 在能源膨胀的情况下, 将废热循环排出, 一般热能系统的热能源都属于矿物燃料, 如 煤炭等, 但很多矿物燃料属于不可再生能源, 在燃烧过程中会 产生有害气体, 严重威胁生态环境, 影响人民群众的生活环境 质量, 为了实现各行业的持续、稳定发展, 企业需要注重节能 减排工作, 实现各项能源的充分利用。另外, 在化学能、热能和 机械能中, 热能系统可以在很多环节节省能源, 这样才能够实 现能源的充分利用, 这就要求相关部门深入分析热能动力系 统优化、节能改造等内容, 有效地改善能源紧张的现状,降低 污染物的排放量, 强化生态环境的保护, 实现各行各业生态效 益的提升, 确保社会经济与生态环境协调发展。

\section{3 发电厂热能动力系统优化及节能改造} 要点

\section{1 合理设置化学补充水系统}

在现代化社会的发展中, 中国发电厂机组主要是抽凝式, 通过分析热能动力系统化学补水的实际情况发现, 发电厂普 
遍在除氧器中补水, 在水温低的情况下, 可以利用相关辅助装 置, 为补水工作的有效实施提供支持。因此, 为了确保化学补 充水系统的经济、高效运行, 热能动力系统化学补水过程中需 要实行加热、喷雾方式, 实现低压加热器的有效应用, 及时地 控制高位能蒸汽量, 优化化学补充水系统工作性能, 利用回收 排气废热方式进行节能改造。

\section{2 蒸汽凝结水的回收利用}

在发电厂实际生产和运行中, 需要大量的工业用水和燃 料能源等资源, 利用这些资源获取蒸汽热力, 实现工业生产的 预期目标。但是, 在生产过程中, 蒸汽释放的热能凝结水会被 丢弃, 这些蒸汽凝结水的蒸汽总热量在 20\% 30\%, 在充分利 用凝结水的情况下, 可以节省更多的工业用水和燃料能源 [2]。 在蒸汽系统节能改造过程中, 相关人员可以利用蒸汽凝结水 的余热代替低压蒸汽,并回收和利用凝结水的余热, 降低低压 蒸汽能量的使用量, 节省更多的能源。另外, 在凝结水回收过 程中, 常用的回收方式是背压回水、会压回水。其中,背压回水 主要是利用疏水阀背压, 将蒸汽凝结水和水蒸气在一定回收 位置中进行传输, 实现二次水蒸气和回收水的充分利用, 有效 地节省更多的能源, 为环境保护工作的实施提供支持。会压回 水主要是利用气动凝结水加压泉针对凝结水做好加压传输工 作, 这种方式的可靠性比较强, 无需用电。这两种回收方式能 够全面应用蒸汽凝结水, 降低锅炉燃烧能源的消耗量, 减少锅 炉向环境中排放的废水和废气,为发电厂创造更多的效益。

\section{3 锅炉废水余热的回收利用}

在除氧器运行过程中, 产生了很多的蒸汽, 会出现严重的 热量损失, 影响人民群众的生存环境,带来严重的能源浪费问 题, 严重影响企业的综合效益。为了有效地改善这一现状,相关 部门需要做好热能动力系统设计工作, 合理地设置冷却器。通 常情况下,锅炉排放污水的方式主要有两种,分别是定期排放 和连续排污。其中, 定期排放主要是污水受到扩容器降压的作 用进行排放,这种排放方式会浪费废水和余热; 连续排污主要 是在排污扩容器的作用下排放污水, 其回收的二次蒸汽相对较 少, 导致污水废热和蒸汽被浪费。因此, 企业需要合理地设置排 污废热回收器, 实现污水余热的充分利用, 并根据锅炉的实际 运行情况, 在冬季将锅炉排水作为采暖用水,在非采暖期间当 作循环系统补充水,实现能源的有效利用,节省更多的能源。

\section{4 发电厂中热能与动力工程的优化对策}

\section{1 做好锅炉养护工作}

为了优化发电厂中的热能与动力工程, 相关人员需要做 好锅炉养护工作, 针对锅炉的阀门和锅炉水位进行养护, 有效
节能与环保 Energy Conservation and Environmental Protection

地减少锅炉运行过程中出现的安全隐患。在锅炉水位养护过 程中, 相关技术人员需要注重重点水位计冲洗、排污处理工 作, 提升发电厂供电的整体质量。除此之外, 在锅炉养护工作 中, 相关人员还需要做好停炉试验, 常用的实验方式是锅炉检 漏试验, 在实际实验过程中, 工作人员需要做好电眼清理工 作。另外, 在锅炉养护过程中, 养护人员需要重点清理燃气管 道, 一般每半年清理一次锅炉燃气管道, 一年清理一次锅炉内 部的水位电极,避免出现锅炉运行质量问题。工作人员常用的 保养方法是干法保养、湿法保养。

\section{2 明确检修人员职责}

为了提高供电的整体质量, 发电厂热能动力系统检验人 员需要提高自身的综合素质和专业水平, 确保动力系统始终 处于稳定的运行状态，并在实际工作中合理地应用各项技术 和原理, 掌握设备结构相关的知识, 提高人员的专业水平, 还 需要定期进行巡视和检测,避免出现故障扩大的问题,并进行 准确判断, 针对存在的问题制定详细的处理方案。

\section{3 设计修改和完善}

在安装完成发电厂热能动力系统后, 相关人员需要进行 测试, 针对系统和分系统进行联试, 分析系统的各项功能和指 标, 及时地修改不满足要求的部分, 以满足系统的各项需求。 通常情况下, 发电厂热能动力系统扩充和完善需要持续很长 的时间,初期立项、设计到施工、安装、调试、评估和验收需要 经历长期过程,一般在两三年, 甚至更长的时间 ${ }^{[3]}$ 。在发电厂 热能动力系统设计初级阶段, 会暴露很多不满足要求的内容, 相关人员需要进行深人分析, 根据客户的实际需求, 合理地提 高和扩充。

\section{5 结语}

综上所述,在社会经济的快速发展中,人民群众越来越注 重环境保护工作。现阶段,发电厂发挥着十分重要的作用,为 工业生产提供了保障,热能动力系统在科学发展观、可持续发 展战略指导下,其优化和节能改造具有重要意义,有利于实现 能源的充分利用,减少对生态环境造成的破坏, 有效地保护生 态环境,实现节能环保的预期目标。

\section{参考文献}

[1]欧丹.内燃机热能动力系统优化与节能改造分析 $[J]$.内燃机与 配件,2018(21):50-51

[2]罗小荣.发电厂热能动力系统优化与节能改造分析 [J].计算机 产品与流通,2017(11):88.

[3]李佳. 发电厂热能动力系统优化与节能改造分析 [J].城市建设 理论研究(电子版),2016(27):18-19. 